\title{
Single-Phase Self-Oscillating Jets for Enhanced Heat Transfer
}

Conference Paper NREL/CP-540-42350 June 2008

\section{Preprint}

S. Narumanchi, K. Kelly, and M. Mihalic National Renewable Energy Laboratory

S. Gopalan and R. Hester Bowles Fluidics Corporation

A. Vlahinos Advanced Engineering Solutions, LLC

Presented at SemiTherm 2008

San Jose, California

March 16-20, 2008 


\section{NOTICE}

The submitted manuscript has been offered by an employee of the Midwest Research Institute (MRI), a contractor of the US Government under Contract No. DE-AC36-99G010337. Accordingly, the US Government and MRI retain a nonexclusive royalty-free license to publish or reproduce the published form of this contribution, or allow others to do so, for US Government purposes.

This report was prepared as an account of work sponsored by an agency of the United States government. Neither the United States government nor any agency thereof, nor any of their employees, makes any warranty, express or implied, or assumes any legal liability or responsibility for the accuracy, completeness, or usefulness of any information, apparatus, product, or process disclosed, or represents that its use would not infringe privately owned rights. Reference herein to any specific commercial product, process, or service by trade name, trademark, manufacturer, or otherwise does not necessarily constitute or imply its endorsement, recommendation, or favoring by the United States government or any agency thereof. The views and opinions of authors expressed herein do not necessarily state or reflect those of the United States government or any agency thereof.

Available electronically at http://www.osti.gov/bridge

Available for a processing fee to U.S. Department of Energy and its contractors, in paper, from:

U.S. Department of Energy

Office of Scientific and Technical Information

P.O. Box 62

Oak Ridge, TN 37831-0062

phone: 865.576 .8401

fax: 865.576 .5728

email: mailto:reports@adonis.osti.gov

Available for sale to the public, in paper, from:

U.S. Department of Commerce

National Technical Information Service

5285 Port Royal Road

Springfield, VA 22161

phone: 800.553 .6847

fax: 703.605.6900

email: orders@ntis.fedworld.gov

online ordering: http://www.ntis.gov/ordering.htm 


\title{
Single-Phase Self-Oscillating Jets for Enhanced Heat Transfer
}

\author{
Sreekant Narumanchi, ${ }^{*}$ Kenneth Kelly, and Mark Mihalic \\ National Renewable Energy Laboratory \\ 1617 Cole Boulevard, Golden, CO 80401-3393 \\ *Email: Sreekant_narumanchi@nrel.gov \\ Phone: 303-275-4062 \\ Shridhar Gopalan and Russ Hester \\ Bowles Fluidics Corporation \\ 6625 Dobbin Road, Columbia, MD 21045 \\ Andreas Vlahinos \\ Advanced Engineering Solutions, LLC \\ 4547 North Lariat Drive, Castle Rock, CO 80104
}

\begin{abstract}
In hybrid electric vehicles (HEVs), the inverter is a critical component in the power module, which conditions the flow of electric power between the AC motor and the DC battery pack. The inverter includes a number of insulated gate bipolar transistors (IGBTs), which are high-frequency switches used in bi-directional DC-AC conversion. The heat generated in the IGBTs can result in degraded performance, reduced lifetime, and component failures. Heat fluxes as high as $250 \mathrm{~W} / \mathrm{cm}^{2}$ may occur, which makes the thermal management problem quite important. In this paper, the potential of self-oscillating jets to cool IGBTs in HEV power modules is investigated experimentally.

A full factorial design of experiments was used to explore the impact of nozzle design, oscillation frequency, jet flow rate, nozzle-to-target distance, and jet configuration (freesurface or submerged) on heat transfer from a simulated electronic chip surface. In the free-surface configuration, selfoscillating jets yielded up to $18 \%$ enhancement in heat transfer over a steady jet with the same parasitic power consumption. An enhancement of up to $30 \%$ for the same flow rate (and velocity since all nozzles have the same exit area) was measured. However, in the submerged configuration, amongst the nozzle designs tested, the self-oscillating jets did not yield any enhancements in heat transfer over comparable steady jets. Results also suggest that oscillating jets provide a more uniform surface temperature distribution than steady jets.
\end{abstract}

\section{Keywords}

Self-oscillating, jets, IGBTs, power electronics, freesurface, submerged, heat transfer, cooling

\section{Nomenclature}

A Area of target surface, $\mathrm{m}^{2}$

AC Alternating current

APEEM Advanced Power Electronics and Electrical Machines

BFC Bowles Fluidics Corporation

$\begin{array}{ll}\text { DC } & \text { Direct current } \\ \text { DOE } & \text { Department of Energy } \\ \text { h } & \text { Heat transfer coefficient, } \mathrm{W} / \mathrm{m}^{2} \mathrm{~K} \\ \text { HEV } & \text { Hybrid electric vehicle } \\ \text { IGBT } & \text { Insulated gate bipolar transistor } \\ \text { lpm } & \text { Liters per minute } \\ \text { NIST } & \text { National Institute of Standards and Technology } \\ \text { NREL } & \text { National Renewable Energy Laboratory } \\ \text { q } & \text { Heat dissipated in the film heater, W } \\ \text { T } & \text { Temperature, } \mathrm{K}\end{array}$

\section{Subscripts}

ref Reference

\section{Introduction}

The overall goal of the FreedomCAR and Fuel Partnership is to reduce petroleum consumption by developing technologies that enable cars and trucks to become highly efficient, through improved power technologies and cleaner domestic fuels. To be effective, these technologies must be competitive in terms of cost and performance [1].

An electric propulsion system is essential for near-term combustion engine HEVs and longer-term fuel cell hybrid vehicles. Electric propulsion systems currently are available in the market but at a cost of approximately $\$ 33 / \mathrm{kW} \mathrm{[2].} \mathrm{The}$ Department of Energy (DOE) Advanced Power Electronics and Electrical Machines (APEEM) activity seeks to reduce this cost to $\$ 12 / \mathrm{kW}$ by 2015 and to $\$ 8 / \mathrm{kW}$ peak by 2020 , thereby enabling large-scale market penetration of advanced, energy-efficient vehicles [3]. The development of low cost, effective thermal management for power electronics and electrical machines is critical for the performance and reliability of the electronics system and for meeting the aggressive program cost targets [4].

The National Renewable Energy Laboratory (NREL) leads research and development activities in thermal control related to the DOE's APEEM program. The overall objective of these 
thermal control activities is to develop advanced technologies and effective integrated thermal control systems aimed at meeting the FreedomCAR program goals for power module volume, cost, and weight.

High heat-transfer rates are required to enable reductions in the cost, weight, and volume of power electronics components. Single-phase jets have been studied very extensively in the literature in the context of electronics cooling [5-8]. Some studies in the literature demonstrated that oscillating jets could enhance heat transfer over steady jets [913]. In some of these studies, the oscillation was induced by mechanical means [9-12], while in others [13] the jets were self-oscillating. Self-oscillating jets involve no moving parts, and the oscillations are induced strictly by pressure differences in the fluid. This makes them quite attractive. However, there is very limited literature on the heat-transfer performance of self-oscillating jets. NREL established a collaboration with Bowles Fluidics Corporation (BFC) to explore the heattransfer performance of different types of fluidic nozzles. To conduct this study, NREL built a test fixture to accurately characterize the heat-transfer performance of different types of fluidic nozzles. Several fluidic nozzles were provided by BFC, and heat-transfer experiments were performed (with deionized water) to characterize the performance of these nozzles. Comparable experiments with non-oscillating, steady jets were also performed to serve as a baseline against which to compare the performance of the fluidic nozzles.
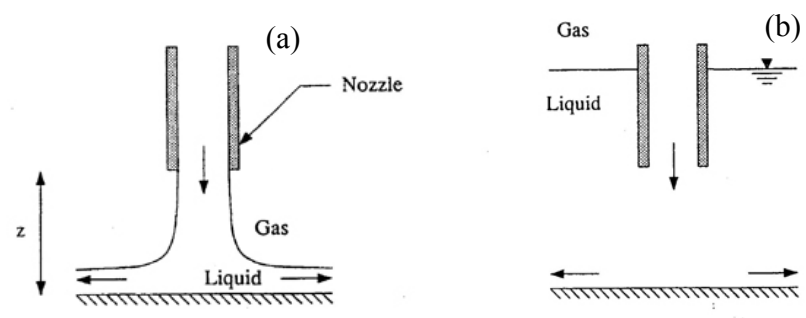

(c)

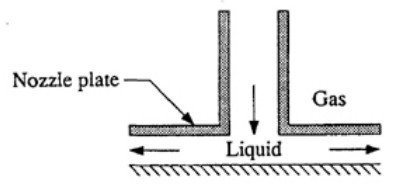

Figure 1: Different jet impingement configurations (taken from [14]): (a) free-surface jet, (b) submerged jet, (c) confined submerged jet.

\section{Description of a fluidic nozzle and self-oscillating jet}

In the literature, the three main categories of jets that have been explored are free-surface, submerged, and confined submerged jets. These are illustrated schematically in Figure 1 (taken from [14]). In a free-surface jet configuration [Figure 1(a)], the liquid jet flows into another fluid-usually a gaswhich is of much lower density than the liquid. In a submerged jet, the liquid jet flows into another fluid of comparable density [Figure 1(b)]. In a confined submerged jet [Figure 1(c)], the liquid jet is submerged, but there is also a plate or wall confining the liquid after impingement on the target surface.

(a)

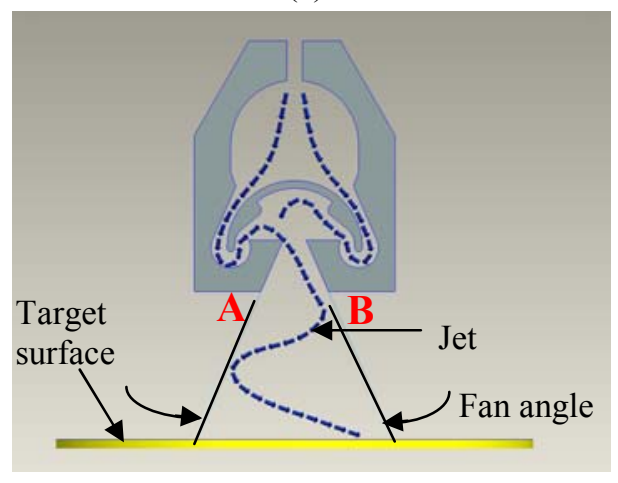

(b)

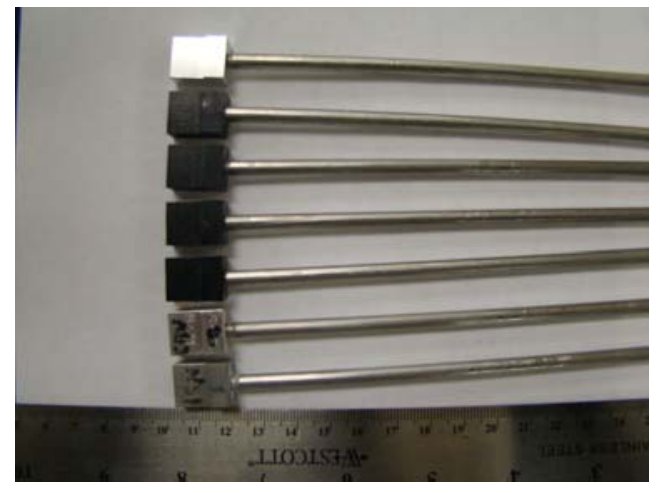

Figure 2: Illustration of the principle behind self-oscillating jets, (a) cross-sectional view of fluidic nozzle, (b) different nozzles tested.

A self-oscillating jet is generated by a fluidic nozzle. Figure 2(a) illustrates the concept behind self-oscillating jets. However, the fluidic geometry illustrated is not an exact representation of the nozzle designs that were tested in this study. The oscillations are caused by the geometry inside the nozzle. The nozzle geometry causes vortices in the fluid, and the interacting vortices and consequent pressure differences in the fluid result in oscillations in the liquid jet at the nozzle exit. The jet oscillates within the angle depicted in Figure 2(a). This angle is referred to as the fan angle. The frequency of these oscillations is determined by the time taken for the jet to go from A to B and then back to A. Essentially, the jet performs a sweeping motion within the fan angle.

In this study, we looked at nozzles that generate selfoscillating jets with different frequencies and fan angles. They are called self-oscillating because no moving parts are required to generate the oscillations. Typically, both the frequency and fan angle are a function of flow rate. Figure 2(b) shows all the different fluidics encased in a housing, and gives a sense of the dimensions. For the particular nozzles used in this study, the oscillations are in a single plane. However, this need not always be the case. Nozzles can be designed to yield oscillations in the out-of-plane direction. 
Further details regarding the nozzles will be discussed in the next section. From a heat-transfer viewpoint, this sweeping motion has the potential to disrupt the boundary-layer growth on the target surface, and thereby enhance heat transfer between the surface and the liquid.

\section{Experimental loop and test fixture}

NREL built a high-heat-flux test loop to conduct experiments with single-phase heat exchangers. A schematic
NREL also fabricated a test fixture to be used with the high-heat-flux test loop to characterize the heat-transfer performance of single-phase jets. The apparatus is shown in Figure 3(b). It consists of two Teflon plates with a transparent polycarbonate cylinder in between. A copper plug $3.8 \mathrm{~cm}$ (1.5") in length and $1.27 \mathrm{~cm}(0.5$ ') in diameter fits snugly in the center of the lower Teflon plate. Teflon serves as an insulation to prevent heat loss and ensure one-dimensional heat flow in the copper plug. The surface of the copper plug
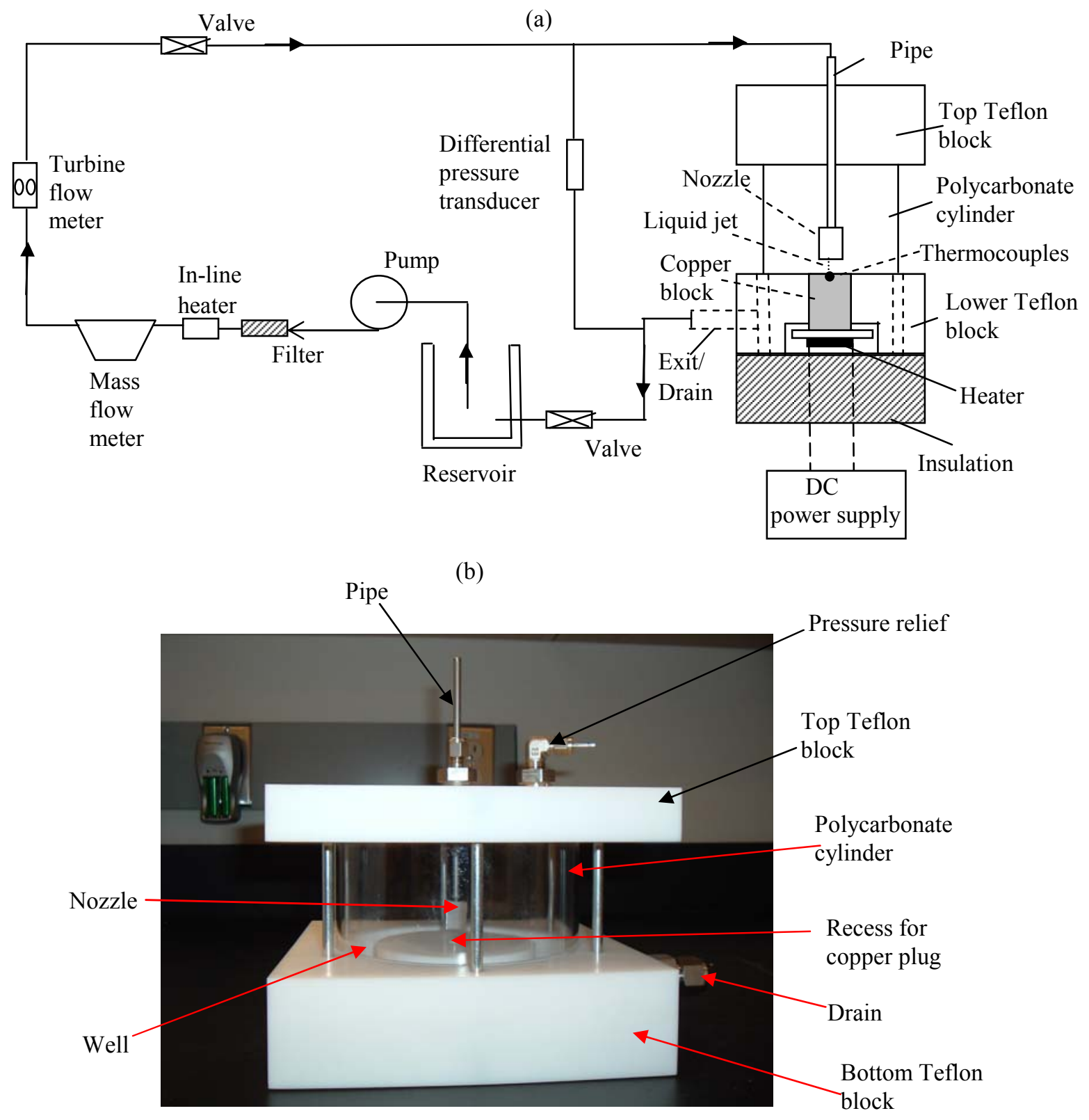

Figure 3: (a) Schematic of test loop, (b) experimental apparatus.

of the loop is shown in Figure 3(a). It consists of a reservoir, pump, filter, mass flow meters, turbine flow meters, and valves for regulating flow rate. The loop is also fully instrumented with pressure sensors for measuring fluid pressure drop, thermocouples for monitoring temperatures, and a data acquisition system controlled by LabView software. 
serves as the target surface on which the jet impinges [Figures 4(a), 4(b)]. We conducted experiments with six different fluidic nozzles. The area of the jet exit of the fluidic nozzles is $1.1 \mathrm{~mm} \times 1.1 \mathrm{~mm}$. The steady-jet nozzle has the same exit area of $1.21 \mathrm{~mm}^{2}$ and has a circular opening of $1.24 \mathrm{~mm}$ diameter. For the steady jet, a circular opening was chosen to make the steady-jet nozzle yield a low pressure drop. The rationale was that this would provide a fair basis for comparison with the performance of the fluidic nozzles.
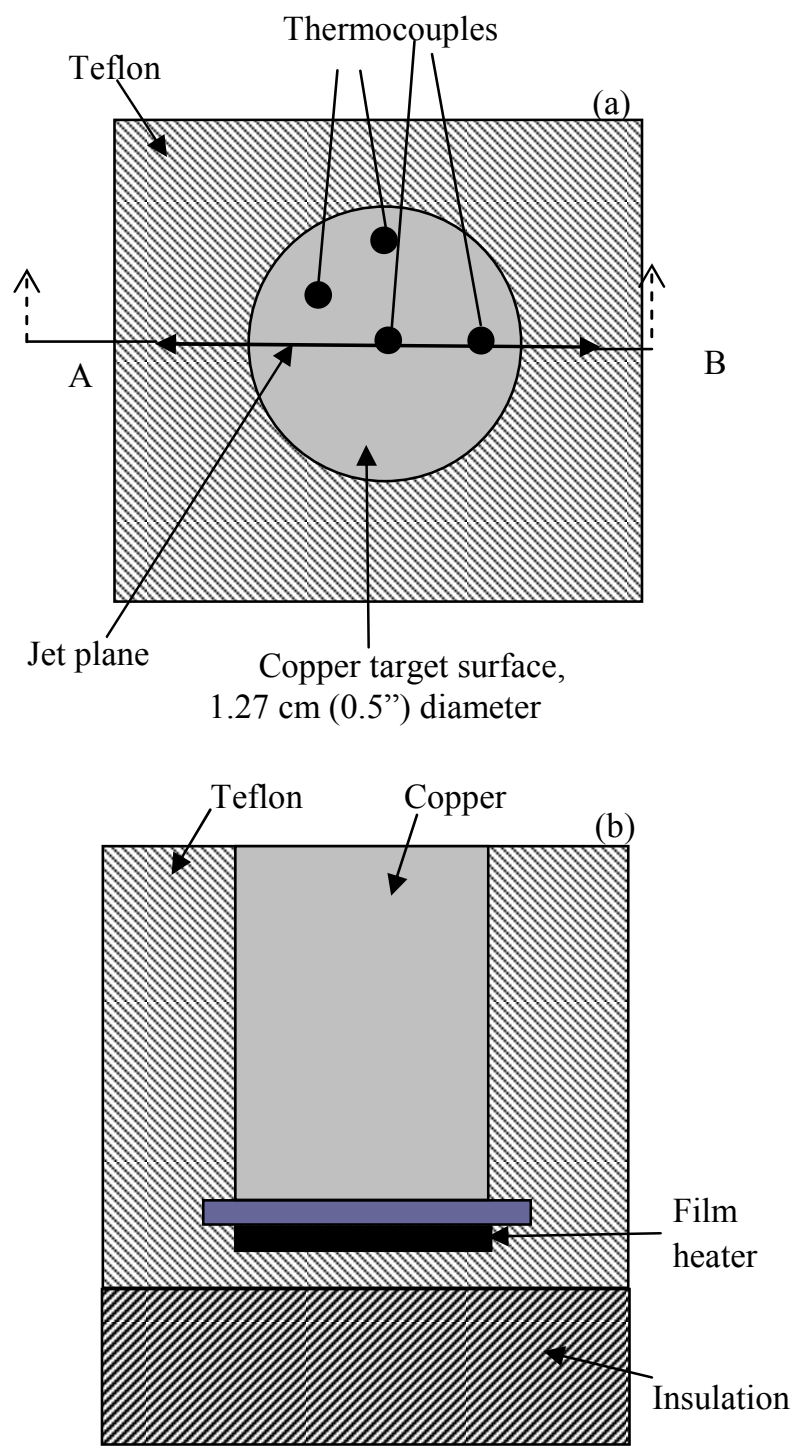

Figure 4: Surface of the copper plug that serves as the target surface (a) top view, (b) cross-sectional view along the $\mathrm{AB}$ axis.

The surface of the copper plug is shown in Figure 4(a). The jet centerline is aligned with the center point of the target. For self-oscillating jets, the plane of oscillation is also shown in the figure. There are four thermocouples on the surface of the copper plug. The rationale for placing multiple thermocouples was to determine the temperature distribution on the target surface. A resistive heater was attached to the back of the copper plug. Thermal grease was placed between the copper plug and the resistive heater to ensure good contact. A thermocouple was also attached to the heater to monitor its temperature. The power was supplied to the heater by a DC power supply. The maximum operating temperature of the heater is rated at $150^{\circ} \mathrm{C}$. Key measurements included the coolant inlet temperature, the coolant outlet temperature, temperatures at four points on the copper target surface, the temperature of the resistive heater, the coolant flow rate, the pressure drop across the jet, and the power input to the heater.

A numerical heat-transfer analysis was done (in FLUENT) on the lower Teflon plate and copper plug to estimate the heat loss from the sides and the back of the apparatus when heat is applied to the resistor. For this analysis, a heat-transfer coefficient was applied to the top of the copper target surface and the surrounding Teflon block. A wide range of heattransfer coefficients characteristic of impinging jets were applied on the copper surface (ranging from 20,000 to 50,000 $\mathrm{W} / \mathrm{m}^{2} \mathrm{~K}$ ). From the simulations, we projected that the heat losses from the sides and back of the apparatus should be no more than $3 \%$. The apparatus was placed on an insulating material with a very low conductivity of $0.02 \mathrm{~W} / \mathrm{mK}$.

\section{Experimental Results and Discussion}

We used a three-level (for velocity and target distance) full-factorial design-of-experiments to evaluate three jet velocities $(2,7$, and $12 \mathrm{~m} / \mathrm{s})$ and three target distances (1.1, 4.4, and $7.7 \mathrm{~mm}$ ) in the free-surface and the submerged configurations (Table 1). Overall, we conducted 126 experiments. This does not include repetitions that were done for some select experiments to establish the repeatability of these experiments.

Using the experimental data, response surface functions for several performance attributes, such as temperature and heat transfer coefficient, were generated as a function of flow rate, target distance, nozzle type, and jet configuration. Three meta models were used - full 2nd-order polynomials, Kriging, and Neural Network. The quality of the response surface functions of all meta models was evaluated based on "goodness of the fit," and the best response surface function was used in data post-processing.

Table 1: Design of experiment variables.

\begin{tabular}{|l|c|c|c|}
\hline Nozzle design & Configuration & $\begin{array}{l}\text { Target } \\
\text { distance } \\
(\mathrm{mm})\end{array}$ & $\begin{array}{l}\text { Flow } \\
\text { rate } \\
(\mathrm{lpm})\end{array}$ \\
\cline { 1 - 1 } Steady & Free Surface & 1.1 & 0.15 \\
\cline { 1 - 1 } Fluidic 1 & & 4.4 & 0.5 \\
\cline { 1 - 1 } Fluidic 2 & & & \\
\cline { 1 - 1 } Fluidic 3 & & 7.7 & 0.87 \\
\cline { 1 - 1 } Fluidic 4 & & & \\
\cline { 1 - 1 } Fluidic 5 & & & \\
\hline Fluidic 6 & & & \\
\hline
\end{tabular}


As mentioned previously, the oscillating jets have an opening dimension of $1.1 \mathrm{~mm} \times 1.1 \mathrm{~mm}$. The baseline steady jet has a diameter of $1.24 \mathrm{~mm}$ and the same area $\left(1.21 \mathrm{~mm}^{2}\right)$ as the fluidic nozzles. The pressure drop versus jet velocity, the fan angle versus velocity, and the frequency versus the velocity characteristics for the nozzles are shown in Figure 5. The behavior of the nozzles is quite diverse. For any given velocity/flow rate [Figure 5(a)], fluidic 1 has the highest pressure drop. As expected, the steady jet nozzle yields the lowest pressure drop. The fan angle versus velocity characteristics [Figure 5(b)] vary widely for the different

(a)

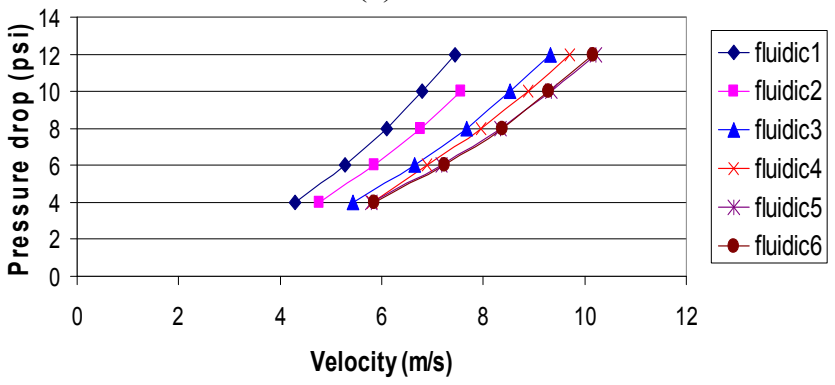

(b)

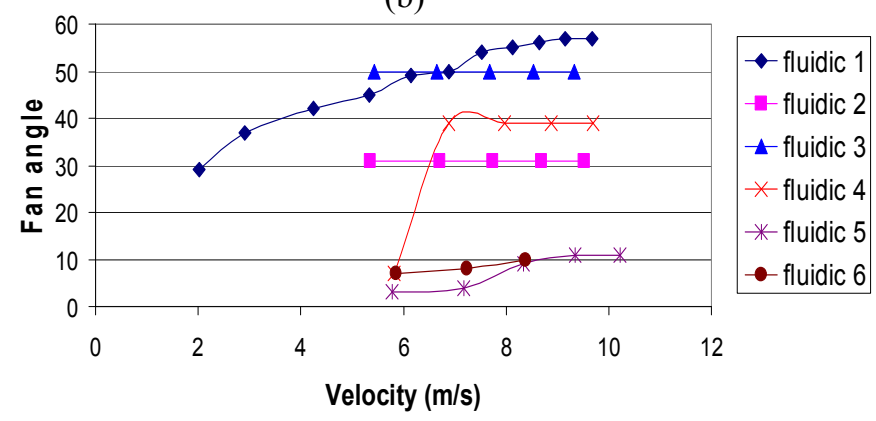

(c)

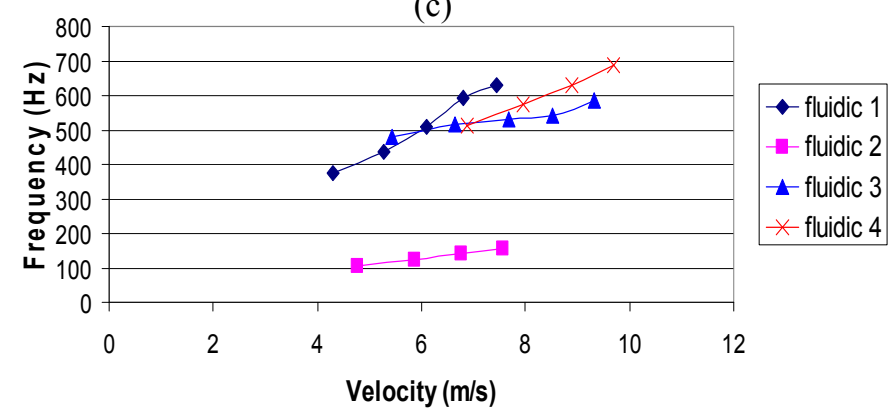

Figure 5: Characteristics of the fluidic nozzles in the freesurface configuration, (a) pressure drop versus velocity, (b) fan angle versus velocity, (c) frequency versus velocity.

nozzles. Interestingly, fluidics 2 and 3 have a nearly constant fan angle over a wide velocity/flow rate range. Fluidics 5 and 6 are closer to a steady jet in the sense that they have a very small fan angle; and because they are unstable, they do not have a well-defined frequency [Figure 5(c)]. For fluidics 1 through 4, the frequency of oscillation increases as a function of flow rate/velocity [Figure 5(c)]. It is worth noting that fluidic 2 has considerably lower frequency of oscillation than the other nozzles. It is important to note that Figure 5 shows the characteristics of the fluidic nozzles in the free-surface [Figure 1(a)] configuration. At this point, the characteristics of the nozzles in the submerged configuration remain to be quantified.

Figure 6 shows the pressure-drop versus flow-rate curves for the nozzles in the free-surface and submerged configurations at a target distance of $1.1 \mathrm{~mm}$. Target distance did not have a significant impact on the pressure. Results with other target distances $(4.4$ and $7.7 \mathrm{~mm})$ look similar to those presented in Figure 6. Configuration (free-surface or submerged) also did not affect the pressure drop. At any given flow rate, fluidic 1 had the highest pressure drop. At most flow rates or velocities (Figure 5), the frequency and fan angle of fluidic 1 were also the highest of the nozzles tested. Figure 6 also shows that the steady jet had the lowest pressure drop at all flow rates for all nozzles.

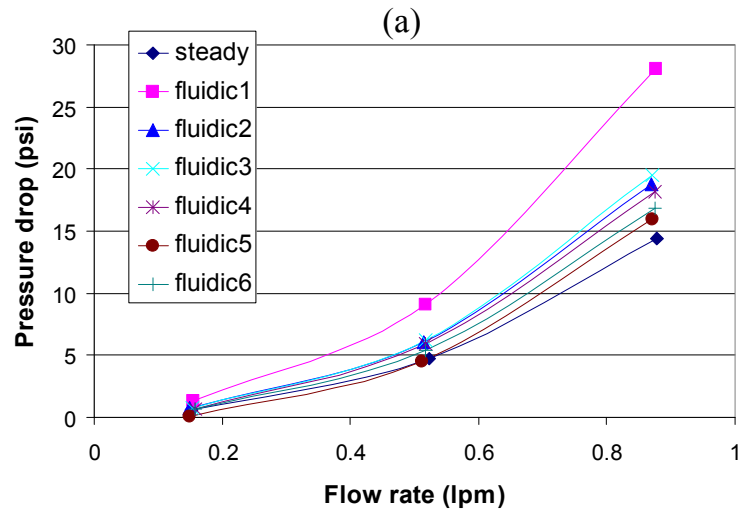

(b)

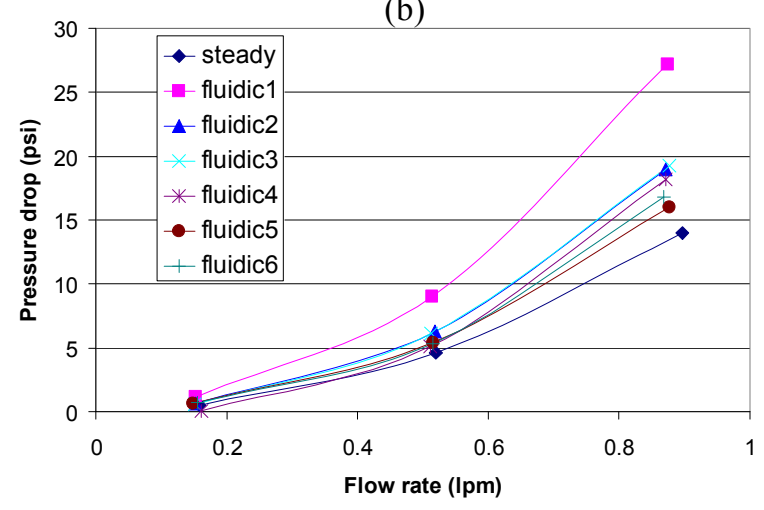

Figure 6: Pressure drop as a function of flow rate with 1.1 $\mathrm{mm}$ target distance, (a) free-surface, (b) submerged.

In the results presented in this study, the heat-transfer coefficient is defined as

$$
\mathrm{h}=\frac{\mathrm{q}}{\mathrm{A}\left(\mathrm{T}-\mathrm{T}_{\text {ref }}\right)}
$$

where $h$ is the heat-transfer coefficient, $q$ is the power applied to the resistive heater, $\mathrm{A}$ is the area of the surface of the copper plug $\left(1.267 \mathrm{~cm}^{2}\right), \mathrm{T}$ is the surface temperature of the copper surface (average of the four thermocouple readings on 
the copper target surface), and $\mathrm{T}_{\text {ref }}$ is the jet inlet temperature. For the experiments reported here, $\mathrm{T}_{\text {ref }}$ is $25^{\circ} \mathrm{C}$.

The experimental uncertainties in the heat transfer coefficients obtained in this study were determined by using the method given by Kline and McClintock [15]. The uncertainty levels presented are analogous to $95 \%$ coverage. The accuracy of the turbine flow meters was $\pm 0.1 \%$ of the flow rate, while the repeatability was $\pm 0.05 \%$ of the flow rate. The accuracy of the mass flow meter was $\pm 0.2 \%$ of the flow rate, while the accuracy of the differential pressure transducer used to measure the pressure drop across the jet was $\pm 0.5 \%$ of the full scale $(0-30 \mathrm{psi})$. Temperature measurements were accurate to within $0.05 \mathrm{~K}$. This includes any error due to the data acquisition system. All thermocouples were calibrated in a temperature bath. The accuracy of the temperature bath was confirmed to be within $0.03 \mathrm{~K}$ of a NIST-traceable temperature

(a)

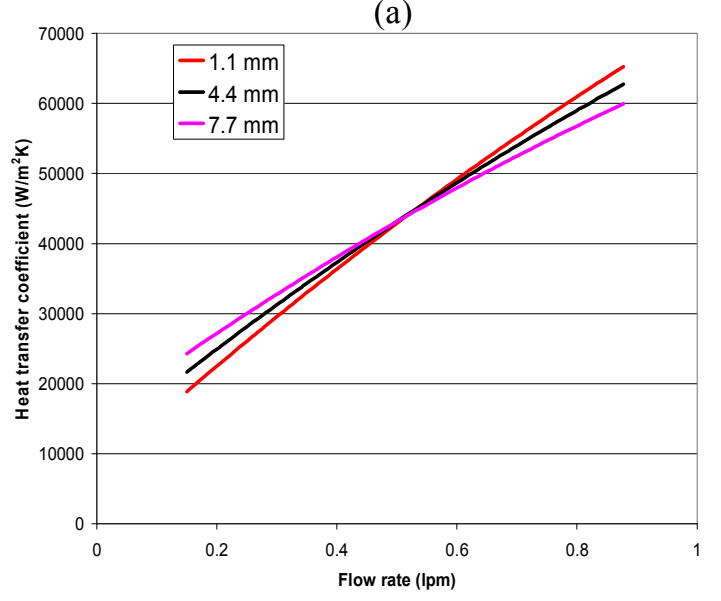

(b)

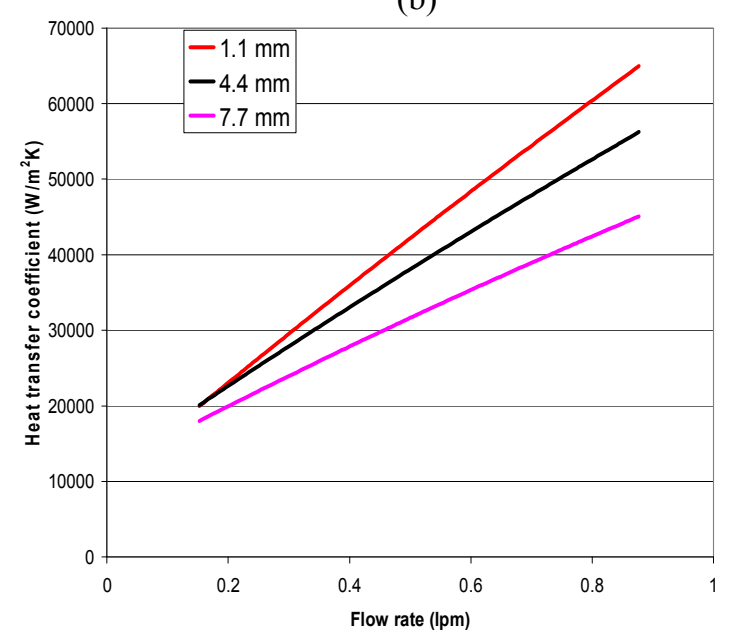

Figure 7: Impact of target distance on heat transfer with fluidic 1 in the (a) free-surface, (b) submerged configuration.

probe within the temperature range of interest $\left(20^{\circ} \mathrm{C}\right.$ to $\left.50^{\circ} \mathrm{C}\right)$. Heat loss from the copper plug of approximately $3 \%$ was also factored into the analysis to yield an uncertainty in the heat transfer coefficient on the order of $\pm 4 \%$. Some select experiments were also performed to deduce the repeatability of the experiments. The repeatability of the heat transfer coefficients was within $2 \%$. In the results presented later, parasitic power loss across the jet (product of pressure drop across the jet and the flow rate) is also a parameter. The uncertainty in the parasitic power was less than $0.6 \%$.

Figure 7 reveals the impact of target distance on heat transfer for fluidic 1 in both the free-surface and submerged configurations. For the free-surface configuration, at lower flow rates a larger target distance yielded a better heat-transfer performance than a shorter target distance. However, at higher flow rates, a shorter target distance yielded higher heattransfer performance than a larger target distance. Overall, in the free-surface configuration, the impact of target distance on heat transfer for the nozzles was noticeable, but not very strong. At low flow rates, the heat-transfer coefficients for the target distances differed by up to $27 \%$; at elevated flow rates, the difference in the heat-transfer performance at different target distances was within $8 \%$.

However, in the submerged configuration, target distance had a big impact on the heat transfer performance of the different fluidic nozzles. As shown in Figure 7(b), as target distance increases, at any given flow rate the heat transfer attenuates. At elevated flow rates, the impact of target distance became even more pronounced. At the lowest flow rate [Figure 7(b)], the difference in heat transfer results for the different target distances was about $10 \%$; for the highest flow rate, the difference was almost $35 \%$ to $40 \%$. Though results are not shown here, similar trends were observed for other fluidic nozzles as well. This aspect was more pronounced for the fluidic nozzles than for the steady jets, because the oscillations and the sweeping motion are damped out with increasing target distance.

Figure 7 reveals that at a short target distance $(1.1 \mathrm{~mm})$, the performance of fluidic 1 in the free-surface configuration was almost identical to that of the submerged configuration. However, at a greater target distance $(7.7 \mathrm{~mm})$, the freesurface configuration yielded much higher heat-transfer performance than the submerged configuration. The reason for this is most likely the damping effect mentioned previously.

Figure 8 shows the heat-transfer performance of different nozzles at the optimum target distance for the free-surface and submerged configurations. This optimum target distance for most cases was $1.1 \mathrm{~mm}$. Figures 8 (a) and 8(b) show the heattransfer coefficients as a function of flow rate and parasitic power, respectively, for the free-surface configuration. Figures $8(c)$ and 8(d) show the same for the submerged configuration.

For any given flow rate, different nozzles have different pressure drops, which means the parasitic power consumed (product of flow rate and pressure drop across the jet) is different. The performance of the different nozzles must be compared for the same parasitic power consumed. This is the rationale for plotting the heat transfer coefficient as a function of parasitic power. Figure 8(a) shows that, in the free-surface configuration, fluidic 1 yielded the highest heat-transfer coefficients at elevated flow rates (beyond $0.5 \mathrm{lpm}$ ). The same figure shows that the steady jet yielded the lowest heattransfer coefficient. This suggests that for a given flow rate, heat transfer was enhanced in the free-surface configuration 
with self-oscillating jets. The results also suggest that in the free-surface configuration, a higher frequency of oscillation leads to increased heat transfer. It is more illustrative to look at Figure 8(b), which shows the heat-transfer coefficient versus parasitic power for the free-surface configuration. Interestingly, this plot shows that fluidic 3 was the best performing nozzle. Fluidic 1 had a higher pressure drop than fluidic 3, so when its heat-transfer performance is plotted against the parasitic power, it did not rank the highest. Figure 8(b) shows that the steady jet was the lowest-performing nozzle in the free-surface configuration. A hypothesis in the reduces the fluid-to-solid heat-transfer resistance. Figure 8 illustrates that, in the free-surface configuration, the fluidic nozzles can yield up to $30 \%$ enhancement over a steady jet at comparable flow rates. For the same parasitic power, the enhancement over a steady jet is about $18 \%$. To get a sense of the numbers, at a flow rate of $0.87 \mathrm{lpm}$ (velocity of $12 \mathrm{~m} / \mathrm{s}$ ), a heat-transfer coefficient of about $65,000 \mathrm{~W} / \mathrm{m}^{2} \mathrm{~K}$ was achieved with fluidic 1.

Figures $8(\mathrm{c})$ and $8(\mathrm{~d})$ show heat transfer versus flow rate and heat transfer versus parasitic power, respectively, for the submerged configuration. Figure 8(c) shows that the curves (a)

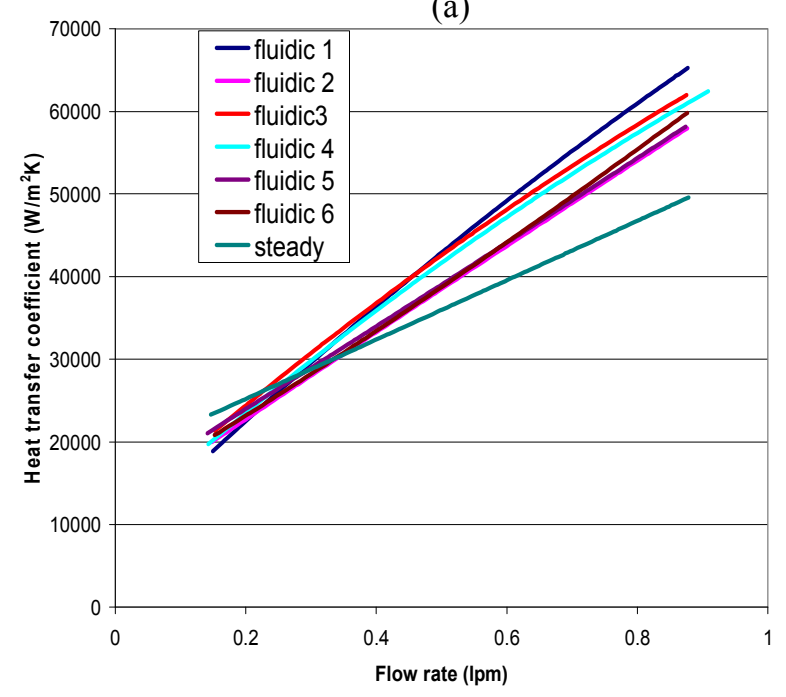

(c)

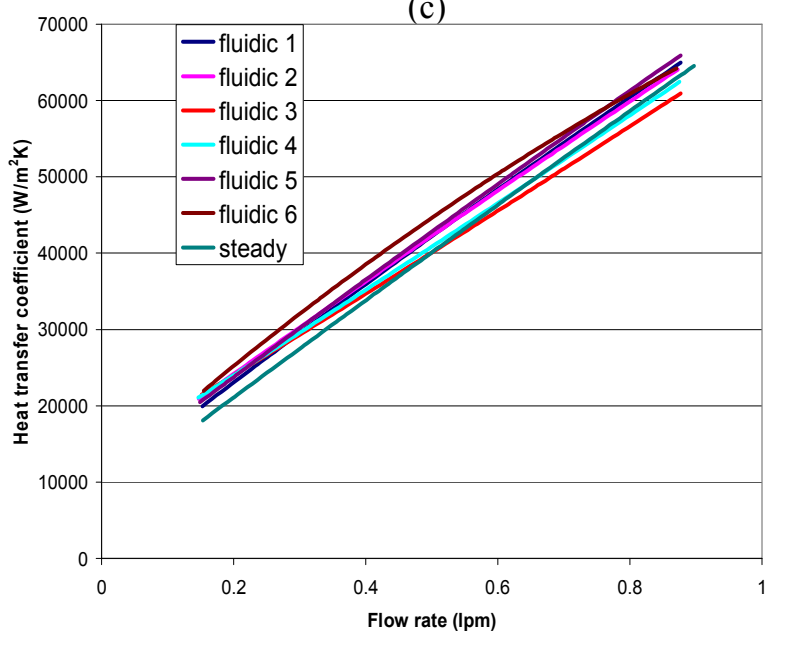

(b)

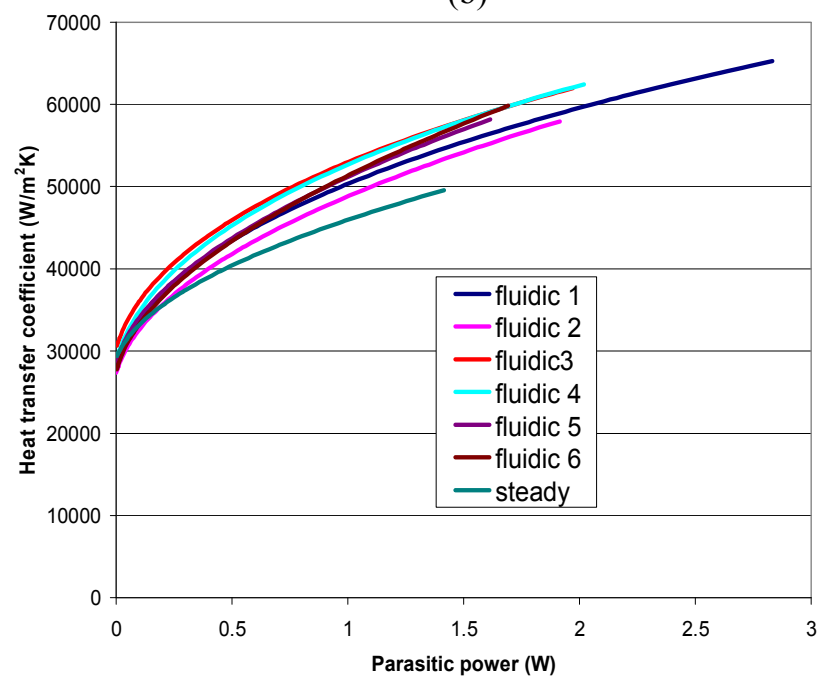

(d)

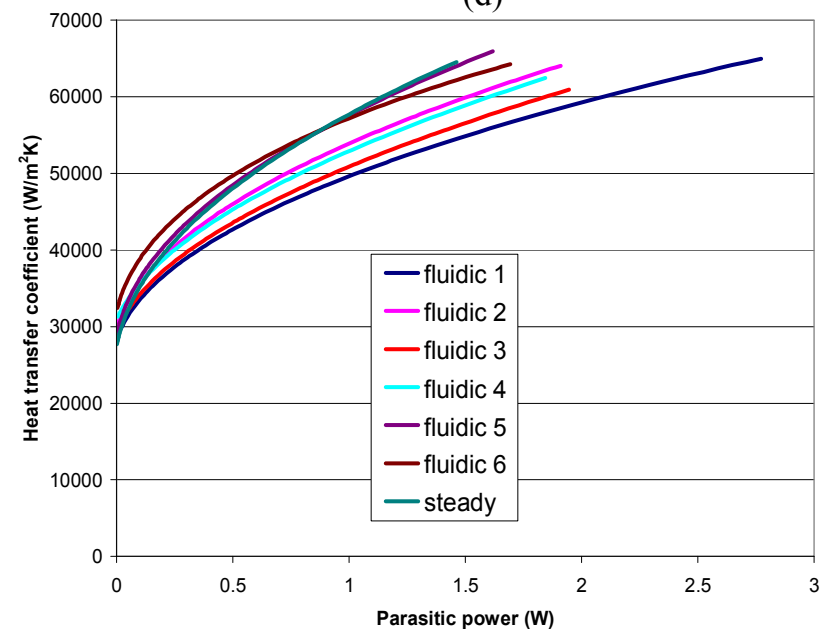

Figure 8: Heat-transfer performance of nozzles at optimum target distance: (a) heat-transfer coefficient (h) versus flow rate in the free-surface configuration, (b) h versus parasitic power in the free-surface configuration, (c) h versus flow rate in the submerged configuration, (d) h versus parasitic power in the submerged configuration.

literature [16] indicates that at elevated flow rates in the freesurface configuration, splashing causes the fluid film to become very thin and causes bulk warming of the fluid because the boundary layer reaches the surface of the film and attenuates the heat-transfer coefficient. Also, at close target distances, the sweeping motion of the oscillating jet causes significant disruptions in the boundary layer growth, which for the nozzles are all linear. There are some differences in the heat transfer results from the nozzles. At low flow rates, the heat-transfer coefficients achieved with the different nozzles were within $20 \%$ of one another; at higher flow rates, they were within $8 \%$ of one another. However, Figure $8(\mathrm{~d})$ shows that fluidic 5 and the steady jet are the best performing nozzles. In the submerged configuration, virtually no 
enhancement was achieved from the self-oscillating jets over a steady jet; i.e., the best performing fluidic nozzles are nearly identical to the steady jet. Another important point is that the best heat transfer at a given parasitic power in the submerged configuration was higher than that in the free-surface configuration.

There may be two reasons for the results seen in Figure 8. First, in the submerged configuration, the steady-jet heattransfer performance picks up because there is no splashing, which is a problem as mentioned earlier for the free-surface steady-jet configuration. Second, in the submerged
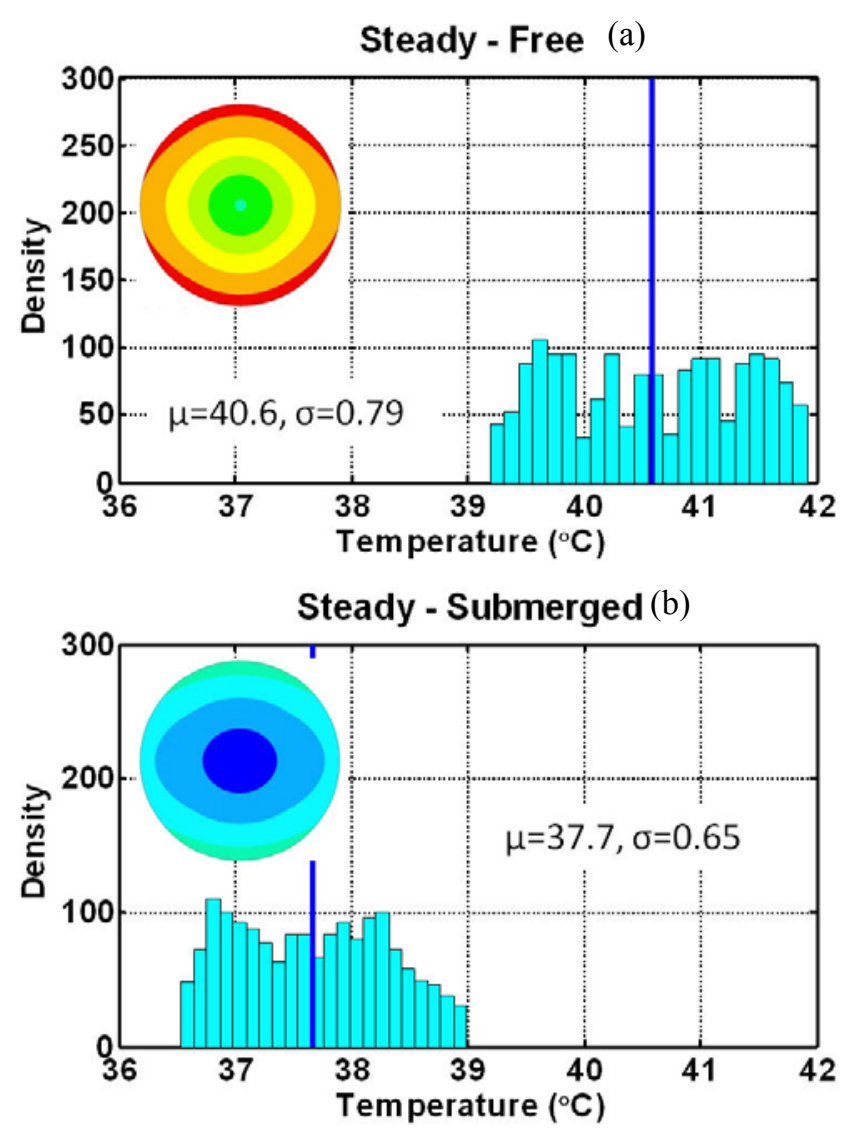

The oscillating jets also appeared to increase the target surface temperature uniformity with respect to steady jets. Uniformity of target surface temperature is important. In a practical IGBT package, uniform temperatures will lead to reduced thermal stresses. Figure 9 shows the distribution of temperature across the surface. The temperatures are derived by a smooth fit of the four thermocouple surface temperature measurements. The mean target surface temperature (dark vertical line) and the standard deviation in the target surface temperature are also shown for the steady jet and the oscillating jet generated by fluidic 3 . Both the free-surface and
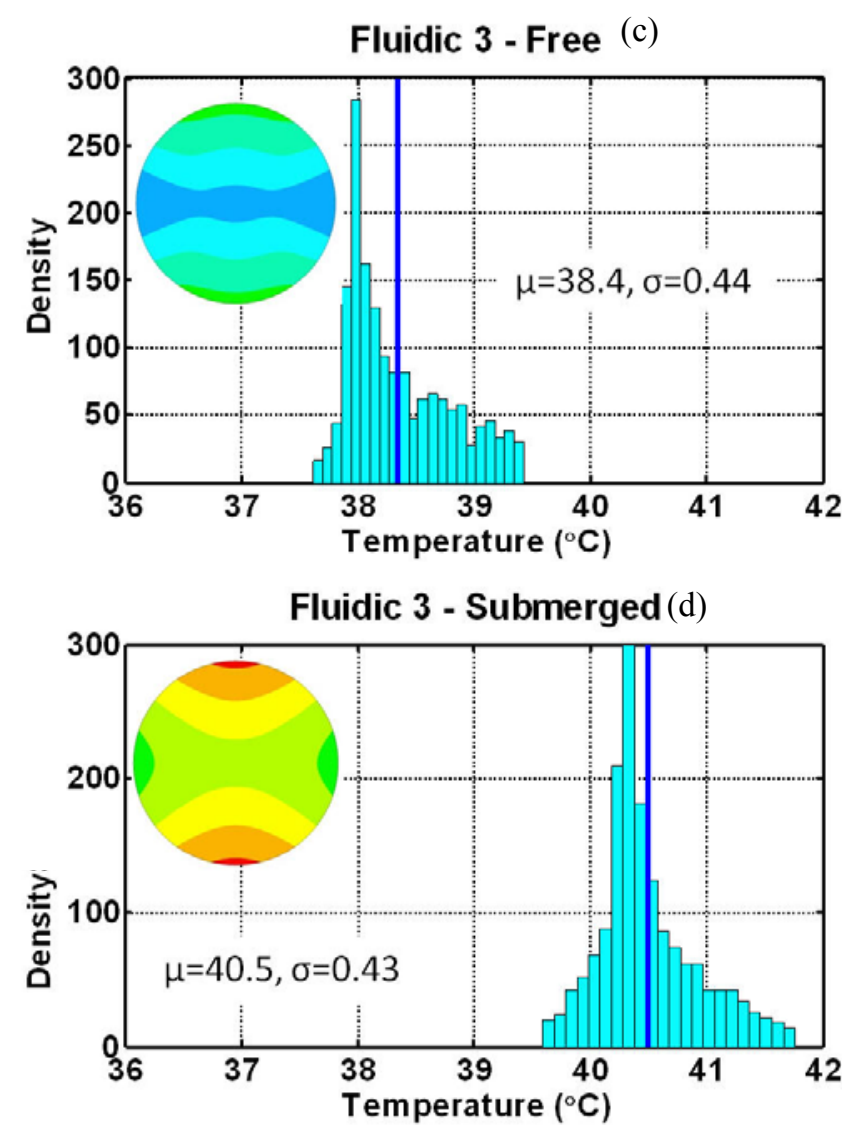

Figure 9: Temperature distribution on the target surface for (a) steady free-surface jet, (b) steady submerged jet, (c) free-surface jet from fluidic 3, and (d) submerged jet from fluidic 3, for a target distance of $4.4 \mathrm{~mm}$, and jet velocity of $7 \mathrm{~m} / \mathrm{s}$.

configuration, the strength of the oscillations of the oscillating jets is somewhat dampened and attenuated. This is particularly true at larger target distances.

Our experiments showed that the steady submerged jet outperformed the steady free-surface jet by almost $30 \%$ in certain cases. This suggests that eliminating splashing and warming of the fluid in the boundary layer for the steady jets is very important. The nozzle characteristics presented in Figure 5 (fan angle versus velocity and frequency versus velocity) are only for the free-surface configuration. These characteristics could change considerably in the submerged configuration. submerged configurations are shown. The results are presented for a target distance of $4.4 \mathrm{~mm}$ and a velocity of 7 $\mathrm{m} / \mathrm{s}$. The $\mathrm{y}$-axes show the temperature distribution on the target surface. The standard deviation of temperatures for the steady jet [Figures 9(a) and 9(b)] is much higher than that of the fluidic 3 jets [Figures 9(c) and 9(d)]. This suggests that oscillating jets are yielding more uniform target surface temperatures in both the free-surface and submerged configurations. It is also worth noting that, for fluidic 3 in the submerged configuration [Figure 9(d)], even though the overall heat transfer is poor compared with that of the steady submerged jet [Figure 9(c)], the temperature uniformity is much better. One interesting fact is that the submerged fluidic 3 jet yields the lowest standard deviation in temperature 
amongst the four cases examined in Figure 9. Further research is needed to determine whether these trends in surface temperature uniformity are consistent among all the cases.

The results presented here with self-oscillating jets are not completely exhaustive. Other nozzle designs, such as larger diameter nozzles and nozzles generating out-of-plane oscillations, which might be better performing than those presented in this paper, could be explored.

\section{Conclusions}

This paper reports on one of the very few experimental studies exploring the heat-transfer potential of liquid selfoscillating jets. We explored the heat-transfer performance of several self-oscillating jet designs. In the free-surface configuration, self-oscillating jets showed enhancements over comparable steady jets of almost $18 \%$ with the same parasitic power loss. For a given flow rate (and hence velocity), without limiting parasitic power loss, free-surface self-oscillating jets enhanced heat transfer up to $30 \%$ over that of a steady jet. In the free-surface configuration, results hinted that a higher frequency of oscillation led to increased heat transfer. However, in the submerged configuration, amongst the fluidic nozzles explored, we did not observe any heat-transfer enhancements with self-oscillating jets over a steady jet. Results suggest that oscillations can also improve the temperature uniformity of a target surface with respect to a steady jet. The nozzle designs that were investigated in this study are not exhaustive, and further variations of nozzle design will be explored in the future.

\section{Acknowledgments}

The authors would like to acknowledge the support provided by Susan Rogers, Technology Development Manager, Advanced Power Electronics and Electric Machines, DOE FreedomCAR and Vehicle Technologies Program of the Office of Energy Efficiency and Renewable Energy. The authors would like to acknowledge Desikan Bharathan and Keith Gawlik for helpful discussions regarding the experimental apparatus.

\section{References}

1. Vehicle Technologies Program, www.eere.energy.gov/ vehiclesandfuels/about/fcvt_mission.html.

2. Energy and Environmental Analysis, Inc., Technology and cost of the MY2007 Toyota Camry HEV - Final Report, Oak Ridge National Laboratory Subcontract report, ORNL/TM-2007/132, 2007.

3. Electrical and Electronics Technical Team, "Electrical and Electronics Technical Team Roadmap," Nov. 2006, www.eere.energy.gov/vehiclesandfuels/pdfs/program/eett _roadmap.pdf, 2006.

4. Kelly, K., et al., "An overview of thermal control technologies for cooling electric vehicle power electronics," Proceedings of the EVS 23 Conference, Anaheim, CA, Dec. 2-5, 2007.

5. Garimella, S.V., "Heat transfer and flow fields in confined jet impingement," in Annual Review of Heat Transfer, pp. 413-494, 2000.
6. Lienhard, J.H., "Liquid jet impingement," in Annual Review of Heat Transfer, pp. 199-270, 1995.

7. Webb, B.W., and Ma, C.-F., "Single-phase liquid jet impingement heat transfer," Advances in Heat Transfer, 26, pp. 105-217, 1995.

8. Narumanchi, S.V.J., Amon, C.H., and Murthy, J.Y., "Influence of pulsating submerged liquid jets on chiplevel thermal phenomena," ASME Journal of Electronic Packaging, 125, pp. 354-361, 2003.

9. Zumbrunnen, D.A., and Aziz, M., "Convective heat transfer enhancement due to intermittency in an impinging jet," ASME Journal of Heat Transfer, 115, pp. 91-98, 1993.

10. Mladin, E.C., and Zumbrunnen, D.A., "Nonlinear dynamics of laminar boundary layers in pulsatile stagnation flows," Journal of Thermophysics and Heat Transfer, Vol. 8, No. 3, pp. 514-523, 1994.

11. Mladin, E.C., and Zumbrunnen, D.A., "Local convective heat transfer to submerged pulsating jets," International Journal of Heat and Mass Transfer, Vol. 40, No. 14, pp. 3305-3321, 1997.

12. Wang, Y., Yuan, G., Yoon, Y.-K., Allen, M.G., and Bidstrup, S.A., "Optimization of synthetic jet fluidic structures in printed wiring boards," ASME Journal of Electronic Packaging, 128, pp. 353-359, 2006.

13. Camci, C., and Herr, F., "Forced convection heat transfer enhancement using a self-oscillating impinging planar jet," ASME Journal of Heat Transfer, 124, pp. 770-782, 2002.

14. Wolf, D.H., Incropera, F.P., and Viskanta, R., "Jet impingement boiling," Advances in Heat Transfer, 23, pp. 1-132, 1993.

15. Kline, S.J., McClintock, F.A., "Describing uncertainties in single-sample experiments," Mech. Eng. (Am. Soc. Mech. Eng.), 75, pp. 3-8, 1953.

16. Womac, D.J., Ramadhyani, S., and Incropera, F.P., "Correlating equations for impingement cooling of small heat sources with single circular liquid jets," ASME Journal of Heat Transfer, 115, pp. 106-115, 1993. 


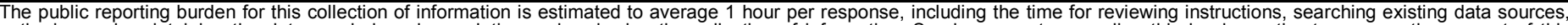

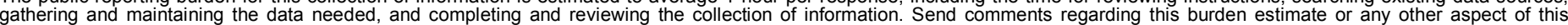

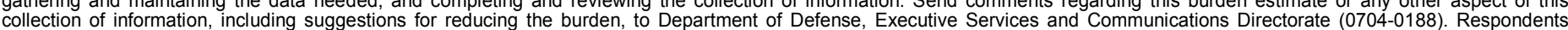

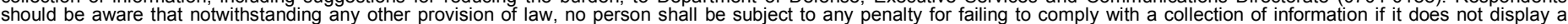

should be aware that notwithstanding

PLEASE DO NOT RETURN YOUR FORM TO THE ABOVE ORGANIZATION.

\begin{tabular}{l|l|l|l} 
1. REPORT DATE $(D D-M M-Y Y Y Y)$ & 2. & REPORT TYPE & 3. DATES COVERED (FrOm - TO)
\end{tabular}

June 2008

Conference Paper

4. TITLE AND SUBTITLE

Single-Phase Self-Oscillating Jets for Enhanced Heat Transfer:

Preprint

5a. CONTRACT NUMBER

DE-AC36-99-G010337

5b. GRANT NUMBER

5c. PROGRAM ELEMENT NUMBER

5d. PROJECT NUMBER

NREL/CP-540-42350

5e. TASK NUMBER

FC087000

5f. WORK UNIT NUMBER
7. PERFORMING ORGANIZATION NAME(S) AND ADDRESS(ES)

National Renewable Energy Laboratory

1617 Cole Blvd.

Golden, CO 80401-3393
8. PERFORMING ORGANIZATION REPORT NUMBER

NREL/CP-540-42350

9. SPONSORING/MONITORING AGENCY NAME(S) AND ADDRESS(ES)

10. SPONSOR/MONITOR'S ACRONYM(S) NREL

11. SPONSORING/MONITORING AGENCY REPORT NUMBER

12. DISTRIBUTION AVAILABILITY STATEMENT

National Technical Information Service

U.S. Department of Commerce

5285 Port Royal Road

Springfield, VA 22161

13. SUPPLEMENTARY NOTES

14. ABSTRACT (Maximum 200 Words)

In hybrid electric vehicles, the inverter is a critical component in the power module, which conditions the flow of electric power between the AC motor and the DC battery pack. The inverter includes a number of insulated gate bipolar transistors (IGBTs), high-frequency switches used in bidirectional DC-AC conversion. The heat generated in IGBTs can degrade performance, reduce lifetime, and cause component failures. Heat fluxes as high as $250 \mathrm{~W}$ per square centimeter may occur, which makes the thermal management problem quite important. In this paper, the potential of self-oscillating jets to cool IGBTs in HEV power modules is investigated experimentally.

15. SUBJECT TERMS

hybrid electric vehicles; inverters; IGBTs; heat transfer; oscillating jets; vehicle power electronics

\begin{tabular}{|c|c|c|}
\hline 16. SECURITY & CLASSIFICAT & N OF: \\
\hline $\begin{array}{l}\text { a. REPORT } \\
\text { Unclassified }\end{array}$ & $\begin{array}{l}\text { b. ABSTRACT } \\
\text { Unclassified }\end{array}$ & $\begin{array}{l}\text { c. THIS PAGE } \\
\text { Unclassified }\end{array}$ \\
\hline
\end{tabular}

\begin{tabular}{l|l}
\hline 17. LIMITATION & 18. $\begin{array}{l}\text { NUMBER } \\
\text { OF PAGES } \\
\text { OF ABSTRACT }\end{array}$ \\
UL & \\
& \\
\hline
\end{tabular}

19a. NAME OF RESPONSIBLE PERSON

19b. TELEPHONE NUMBER (Include area code) 